\title{
Outcome and recovery in first-episode psychosis $^{\dagger}$
}

\author{
Paddy Power
}

\section{Summary}

There is now a good body of evidence about factors that determine outcome and recovery in a first episode of psychosis. However, so far, this is of limited benefit when making predictions at an individual level. Treatment protocols are one size fits all and the recommended duration of medication remains unclear. What is needed is a more sophisticated approach to predicting outcomes and tailoring treatment options to the individual. Removing predisposing factors is an important aspect of this.

\section{Declaration of interest \\ None.}

\section{Copyright and usage}

(c) The Royal College of Psychiatrists 2017.
Paddy Power is a Consultant Child \& Adolescent/Adult Psychiatrist with the Young Adult Service, St Patrick's Mental Health Services and Honorary Senior Lecturer at Department of Psychiatry, Trinity College Dublin. His research interests are in early intervention in psychosis and youth mental health

What is the likely outcome after a first episode of psychosis? Can clinicians advise with confidence that a return to normal life is possible for some patients and how long is that likely to take? Which factors influence this and which interventions should clinicians be recommending? What about the group of patients with first-episode psychosis (FEP) who are unlikely to recover? In this issue, Lally et al provide an insight into some of these questions but there are many more left unanswered. ${ }^{1}$

Outcome in FEP consolidates within the first 3-5 years (known as the 'critical period'). ${ }^{2}$ It depends on a wide range of potentially unrelated factors. These include (a) the severity, duration and type of psychosis; (b) complicating affective and negative features; (c) the influence of comorbid and premorbid problems such as addictions; (d) the characteristics, resilience, reaction and help-seeking behaviour of the individual affected; (e) exposure to environmental influences, stress, family/social reactions and stigma; and (f) the treatments, side-effects, services and supports available. Determining how much each affects outcome in an individual and what services can do about them remains unclear.

\section{Determining outcome in FEP}

Older studies about the course and outcome in FEP are dominated by the Kraepelinean view that non-affective psychosis is a progressive chronic condition with enduring deficits whereas affective/bipolar psychosis is episodic. However, in reality, there is considerable overlap between the two and the initial years of non-affective psychosis are characterised by remissions and relapses. ${ }^{3-5}$ Furthermore, in recent years, this simple dichotomous view of outcome in FEP is being challenged on several fronts.

First, the clinical staging model of psychosis adopts the approach taken in cancer staging. ${ }^{6}$ Illness progression is measured

${ }^{\dagger}$ See pp. 350-358, this issue. in steps or stages. Each stage has its own relative risk of progressing to the next stage within a defined period. Outcome is measured by (a) the speed and (b) likelihood one stage will progress to the next. Stage one is the pre-psychotic clinical stage of ultra-high risk. Stage two is the first acute episode, stage three is the phase of relapses with remissions, and stage four is the chronic treatment-refractory unremitting stage. Studies suggest that $18 \%$ of individuals progress from stage one to stage two within 6 months (increasing to $36 \%$ within 3 years). ${ }^{7}$ Likewise, only $6 \%$ progress from stage two to stage four within the first year of treatment (increasing to $23 \%$ within 10 years). ${ }^{8,9}$ Progression at each stage may not necessarily depend on the same factors and the best treatments may be stage specific. ${ }^{10}$

Second, rather than viewing each psychotic disorder as distinctly separate conditions with their own individual trajectories and outcomes, psychosis is instead seen as a far more dynamic multidimensional process, the end result of an accumulation of multiple interacting risks and protective factors over time. It is analogous to the build-up of factors with age that ultimately lead to an event such as a myocardial infarction, such as the cumulative effects of genetics, diet, weight, cholesterol, smoking, exercise and stress. Simply categorising a psychotic episode by one of these factors alone, such as 'cannabis psychosis', would be like categorising patients who have heart attacks into 'smoking myocardial infarctions' or 'non-smoking myocardial infarctions', treating them differently, and assuming very different outcomes. There are many risk factors for psychosis and each patient is likely to have their own unique constellation. It is this unique combination that is likely to determine individuals' outcomes and should be the focus of planning when designing individual care plans.

Third, psychotic symptoms occur in many mental illnesses not just schizophrenia and bipolar disorders. Kelleher et al highlight this very effectively in a large study revealing the high prevalence of hallucinations in as many as $24 \%$ of patients with common mental disorders such as anxiety disorders. ${ }^{11}$ Are psychotic symptoms therefore an integral part of these conditions, or an indicator of severity - occurring only at the extremes of these acute episodes in the same way as seen in manic or depressive episodes of bipolar disorder? What relevance have psychotic symptoms then to outcomes in these conditions? Are they only seen in individuals with additional risk factors for psychosis? Do they warrant the same interventions as traditional episodes of 
psychosis? Are they followed by the same deficits and outcomes? Are they a marker of poor prognosis?

Finally, there is no clear boundary between more normative anomalous psychotic-like experiences (PLEs) and the clinical syndrome of psychotic disorder. Indeed, PLEs are common in the general population affecting $10-17 \%$ of adults. ${ }^{12}$ This raises the question of at what stage do PLEs become a psychotic disorder - when they become distressing or if they persist beyond a set period of time? The prevalence of PLEs poses a challenge to how we define remission in psychosis. One can have recovery without remission. Indeed, a certain degree of paranoia and inner 'voices' may be an indication of healthy functioning and creativity. It becomes rather subjective whether they are defined as appropriate or pathological to a person's social environment.

\section{Measuring outcome in psychosis}

Are we overly reliant on psychosis measures in determining outcome? Such measures as 'response', 'remission', 'relapse', 'refractory psychosis', although helpful, only portray part of the picture. Equally important is monitoring the course of comorbidities that may not necessarily follow the same trajectory of psychotic symptoms, for example post-psychotic depression, suicidality, cognitive deficits and negative symptoms, unwanted treatment effects, incapacitating psychological reactions such as self-stigmatisation and, finally, complicating physical illnesses/ mortality. 'Functional recovery' may give a broader measure of outcome but it tends to lag behind symptomatic remission by months if not years. This may be a reflection of secondary comorbidities experienced after a psychosis and the practical time it takes to establish one's role in society (after months/years of dislocation) rather than one's true functional capacity.

The internationally agreed definitions of 'remission' and 'recovery' may be very applicable to chronic illnesses but not after the first episode. ${ }^{13}$ Relying on achieving a minimum of 6 months of remission and 2 years of recovery will not only fail to capture the episodic cyclical nature of these illnesses but also how each repeated episode/relapse reduces the likelihood of remission and recovery. A shorter minimum duration, such as 1 month of remission and 6 months of recovery, is far more likely to capture the true extent of remission and recovery from the first episode.

\section{Predicting outcomes and prognosis}

Are we any closer to predicting outcome in FEP? The metaanalysis by Lally et al $^{1}$ in this issue provides a robust evidence base of overall outcomes for patients with FEP. It also highlights very intriguing differences in outcomes in different continents and changes over the past few decades. But it cannot make distinctions at an individual level. Ideally, what we and our patients need now is an evidence base that can inform us better at an individual level about how different treatment and lifestyle choices (e.g. whether to stop using cannabis or take medication for another year) have an impact on outcomes. A 'decision tree analysis' is one way of distinguishing the different outcomes depending on which 'branch' one choses. It has been successfully modelled in economic evaluations of early intervention services. ${ }^{14}$ However, to capture the complexity and multiplicity of factors that determine diagnosis and outcome in FEP one might resort to a 'decision tree forest' model with each tree representing a particular domain of influence such as genetic, drugs, traumas, treatments, physical health. The recent availability of 'big data' such as centralised electronic health records makes the populating and testing of such complex models feasible. These mathematical modelling techniques could be used not only to map the factors involved in the evolution of a psychosis (i.e. the roots and origins of the psychosis) but also to predict a variety of outcomes depending on which option/branch is chosen.

Up to now, one of the problems in making these predictions is that we do not have a baseline for the natural history and course of untreated psychotic disorders. There are few outcome studies of untreated patients and even these have had some form of intervention without medication. What some of these studies show is that a surprisingly large minority of patients with FEP who consistently refuse antipsychotic medication can still achieve remission $(41 \%)$ and a functional recovery $(33 \%){ }^{15}$

\section{Recovery and outcome in FEP}

Recovery is more than simple remission of psychotic symptoms and return to premorbid functioning. It is not just a passive response to treatment. Nor is it just understanding one's prognosis and engaging with the treatments recommended. Recovery is a far more complex process. It demands change and adaptation. It requires tackling the antecedents that triggered the psychosis in the first place. If psychosis is the natural end result of an accumulating array of risk factors over time (genetics, early neurodevelopmental insults, childhood traumas, drugs in adolescence and stress), then addressing these issues is an important part of long-term recovery and relapse prevention. Returning to the same set of circumstances and lifestyle that originally precipitated the psychotic episode may actually be the least healthy outcome.

Recovery includes emotional and psychological dimensions, coming to terms with the shock of losing one's mind, the embarrassment, reconnecting with reality, letting go the fantasies, making sense of what happened, getting one's life back on track, one's routine, re-establishing one's goals, reputation, self-esteem and social network. It may not necessarily result in one returning to one's previous developmental trajectory as what is required is adaptation to a new set of circumstances. A more complete recovery requires understanding, learning from, integrating, assimilating and coming to terms with the whole experience in a way that hopefully resolves some of the predisposing factors that may have contributed to the episode in the first place and reduces the risk of future episodes. Influencing and measuring these outcomes is the real challenge.

Paddy Power, MD, MRCPsych, Young Adult Service, St Patrick's University Hospital, James St, Dublin, D08 K7YW, Ireland. Email: ppower@stpatsmail.com

First received 12 Jun 2017, final revision 2 Oct 2017, accepted 4 Oct 2017

\section{References}

1 Lally J, Ajnakina O, Stubbs B, Cullinane M, Murphy KC, Gaughran F et al. Remission and recovery from first-episode psychosis in adults: systematic review and meta-analysis of long-term outcome studies. Br J Psychiatry 2017; 211: 350-8

2 Birchwood $M$, Todd $P$, Jackson C. Early intervention in psychosis: the critical-period hypothesis. Int Clin Psychopharmacol 1998; 13: S31-40.

3 Craddock N, Owen MJ. The beginning of the end for the Kraepelinian dichotomy. Br J Psychiatry 2005; 186: 364-6.

4 Weirsma D, Neinhuis FJ, Slooff CJ, Giel R. Natural course of schizophrenic disorders: a 15 year follow-up of a Dutch incidence cohort. Schizophr Bull 1999; 24: 75-85.

5 Robinson D, Woerner MG, Alvir JM, Bilder R, Goldman R, Geisler S, et al. Predictors of relapse following response from a first episode of schizophrenia or schizoaffective disorder. Arch Gen Psychiatry 1999; 56: 241-7. 
6 McGorry PD, Hickie IB, Yung AR, Pantelis C, Henry J, Jackson HJ. Clinical staging of psychiatric disorders: a heuristic framework for choosing earlier, safer and more effective interventions. Aust N Z J Psychiatry 2006; 40 616-22.

7 Fusar-Poli P, Bonoldi I, Yung AR, Borgwardt S, Kempton MJ, Valmaggia L, et al. Predicting psychosis meta-analysis of transition outcomes in individuals at high clinical risk. Arch Gen Psychiatry 2012; 69: 220-9.

8 Edwards J, Maude D, McGorry PD, Harrigan SM, Cocks JT. Prolonged recovery in first-episode psychosis. Br J Psychiatry 1998; 172 (suppl 33): 107-16.

9 Demjaha A, Lappin JM, Stahl D, Patel MX, MacCabe JH, Howes OD, et al. Antipsychotic treatment resistance in first-episode psychosis: prevalence subtypes and predictors. Psychol Med 2017; 47: 1981-9.

10 Fusar-Poli P, McGorry PD, Kane JM. Improving outcomes of first-episode psychosis: an overview. World Psychiatry 2017; 16: 251-65.
11 Kelleher I, Devylder JE. Hallucinations in borderline personality disorder and common mental disorders. Br J Psychiatry 2017; 210: 230-31.

12 Johns L, Van Os J. The continuity of psychotic experiences in the general population. Clin Psychol Rev 2001, 21: 1125-41.

13 Bebbington $\mathrm{P}$, Craig T, Garety $\mathrm{P}$, Fowler D, Dunn G, Colbert $\mathrm{S}$, et al. Remission and relapse in psychosis: operational definitions based on case-note data. Psychol Med 2006; 36: 1551-62.

14 McCrone PR, Dhanasiri S, Patel A, Knapp M, Lawton-Smith S. Paying the Price: The cost of Mental Health Care in England to 2026. King's Fund, 2008.

15 Conus $\mathrm{P}$, Cotton SM, Francey SM, Donoghue B, Schimmelmann B, McGorry PD, et al. Predictors of favourable outcome in young people with first episode psychosis without antipsychotic medication. Schizophr Res 2017; 185: 130-6.

\section{psychiatry in music}

\section{Idles: 'Stendhal Syndrome'}

\section{Gary Woods}

'Stendhal Syndrome' is the ninth track on Brutalism, the debut LP from Bristol post-punk five-piece, Idles. The song rails against the ignorant dismissal of art by the ill-informed or those full of 'hot air'. Its Iyrics include several wonderfully puerile playful critiques of works by Bacon, Basquiat and Bellingham, opening with the memorable: 'Did you see that painting what Rothko did? Looks like it was painted by a two-year-old kid'.

The song's title was inspired by vocalist Joseph Talbot's experience in a Valencian gallery, which rendered him awestruck, tearful and 'captivated to the point of nausea'. His subsequent enquiries revealed that the phenomenon had previously been documented in the medical literature where it has also been referred to as Florence syndrome or hyperkulturemia. Stendhal syndrome is an acute and transient mental state disturbance, which typically follows exposure to captivating works of art. Individuals experience prominent anxiety symptoms including tachycardia, dizziness and syncope, with affective or psychotic symptoms also commonly observed.

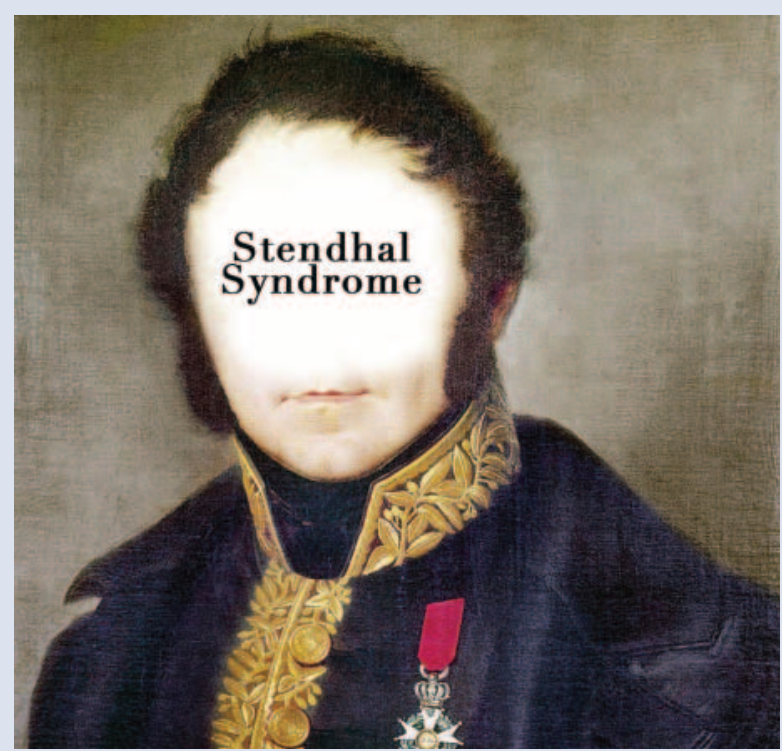

The single's artwork. (c) 2017 Idles. Reproduced by permission.

The Italian psychiatrist Graziella Magherini christened the condition Stendhal syndrome in reference to a pseudonym of the 19th-century French author Marie-Henri Beyle, who had in 1817 written of becoming overwhelmed by the Italian Renaissance artworks he had observed during a trip to Florence. In 1989, while chief of psychiatry at the city's Santa Maria Nuova Hospital, Magherini published a detailed case series of more than 100 tourists affected between 1977 and 1986, often after visiting the famous Uffizi Gallery. With a previous psychiatric history observed in approximately half her sample, Magherini concluded that the condition was frequently associated with a latent psychological disturbance that manifests itself as a reaction to profound works of art.

Stendhal syndrome demonstrates similarities with other city-specific disorders such as Jerusalem syndrome and Paris syndrome, overlapping most closely with the former. In addition to Beyle's description, it has been proposed that the psychoanalysts Freud and Jung both wrote of their experiences of Stendhal syndrome, at the Acropolis of Athens and Pompeii respectively. While discussing the single's entertaining promotional music video, featuring footage from several London galleries, Idles' bassist Adam Devonshire has revealed that his apparent stereotypies were gin-fuelled rather than indicative of an episode of the syndrome. 